\title{
COMO CRIANÇAS PERCEBEM, IDEALIZAM E REALIZAM O LUGAR ONDE MORAM
}

\section{Ariane Kuhnen \\ Scheila Machado da Silveira}

Resumo: Este trabalho apresenta resultados de dois projetos, um de pesquisa e outro de extensão universitária, que se co-relacionam. Objetivaram conhecer os contextos de apropriação espaço-temporal de lugar e a implicação para a formação de seres cidadãos. Os sujeitos são crianças moradoras de uma região periférica de Florianópolis, em Santa Catarina. Utilizaram-se nos dois projetos métodos variados de investigação e intervenção. Entre eles, imersão em campo, observação livre e participante, entrevistas, passeios dirigidos, atividades lúdicas, desenhos e fotografias. Os recursos metodológicos comprovadamente demonstraram ser um importante modo de apreensão da realidade, já que alcançaram percepções e significações dos sujeitos. As fontes teóricas que fundamentaram a intervenção e a análise foram primordialmente originárias da Psicologia Ambiental. Os dados foram analisados qualitativamente. Os resultados demonstram que esses sujeitos têm identidade com a sua comunidade, porém, em relação aos outros lugares da cidade, verificou-se o fenômeno de "guetificação" e, conseqüentemente, desconhecem a cidade além dos limites de seu bairro.Viu-se como essa limitação dos e nos espaços da cidade reflete-se na constituição de sujeitos-cidadãos.

Palavras-chave: Criança. Apropriação. Cidade. Pobreza. Ambiente.

\section{A vida cotidiana e a apropriação da cidade}

Num contexto de profundas mudanças, tanto urbanas quanto naturais, alguns aspectos da vida na cidade chamam bastante a atenção. As mudanças na paisagem 
representam, sem dúvida, a expressão concreta da atividade humana. Elas respondem às necessidades dos indivíduos relativas ao seu enraizamento, que se expressa pela apropriação. Milton Santos lembra:"a paisagem nada tem de fixo, de imóvel. Cada vez que a sociedade passa por um processo de mudanças, a economia, as relações sociais e políticas também mudam em ritmo e intensidade variadas. A mesma coisa acontece em relação ao espaço e à paisagem que se transforma para se adaptar às novas necessidades da sociedade" (Santos, 1978, citado por Veras da Veiga, 1993, p.18). O crescimento demográfico e, especialmente, o desordenamento das cidades brasileiras levaram a graves problemas comprometendo a qualidade de vida da população, em particular a menos favorecida economicamente. Se junta a isso a degradação socioambiental, o uso inadequado dos recursos naturais e a falta de ações políticas efetivas. Essa realidade gera conflitos de interesses substanciados nas dificuldades de concretização da vida urbana. Se faz necessário articular estratégias de envolvimento social.

Debruçar-se sobre essa tarefa parece-nos um dos caminhos a ser triIhado pela universidade brasileira na busca da legitimação de sua função social. A pesquisa e, de forma particular e a ela vinculada, a extensão como o momento mais intenso em que a universidade se lança à sociedade $\mathrm{e}$ estabelece uma troca de saberes, podem ser definidas visando a transformações sociais, vinculando-se ao projeto de juntar-se à sociedade, tornando-a ou mesmo tendo que se constituir verdadeiramente uma comunidade educativa (Gómez-Granell \& Vila, 2003). O horizonte que se coloca é viabilizar que o sistema educativo se envolva no tecido social da cidade, levando e assumindo o projeto de que a cidade "entenda e assuma que a educação é um elemento estratégico imprescindível para seu desenvolvimento harmônico e democrático" (p. 17). A formação para a cidadania deve ser capaz de transformar a informação em conhecimento. Os projetos aqui descritos pretendem atender tal chamado. Elegemos trabalhar com o grupo que talvez seja o mais excluído de nossas cidades - as crianças e jovens. Lordelo, Carvalho e Koller (2002), Castro (2001a, 2001b), Tonucci (2003) vêm alertando para tal necessidade, justificando-a pela premência de se pensar os contextos de vida em termos de condições que favoreçam o desenvolvimento pleno, desde o nutricional até o psíquico, e de que crianças e jovens tenham garantias de existência com qualidade de vida. Estudos feitos com crianças e jovens no campo da ecologia dos comportamentos sociais ou da influência do agenciamento espacial, assim como da incidência do ambiente construído, ou natural, sob os processos de interação social, demonstram como intervêm nos processos de regulação dos comportamentos (Campos-de-Carvalho, 2003; Elali, 2003; Higuchi, 2003; Legendre, 1999; Mekideche, 2005; Oliveira, 2004).

É da cidade, enquanto espaço público, que depende a vida cotidiana. Mas a cidade "não se dá a conhecer naquilo que ela explicita... é na sua 'visibilidade' que ela esconde seus segredos. Como paisagem, a imagem 
cidade é um cenário, uma floresta de signos e sentidos. Como conceito, é uma possibilidade de conhecimento, um campo de saber e, portanto, uma maneira de poder" (Pechman, 1994, pp. 1-2). O mundo humano não se define somente pela totalidade da sociedade global, pela história e pela cultura ou, ainda, pelas superestruturas políticas permeadas de ideologia, mas também pela mediação da vida cotidiana. Intrinsecamente relacionada, a ordem social só existe na medida em que a atividade humana continua a produzi-la. A vida cotidiana aparece, então, como uma realidade interpretada pelos homens e por eles dotada de sentido quando organizam um mundo decifrável e coerente, com elementos rotineiros, ou mesmo quando integram novos conceitos à rotina diária. Suas ações requerem, fundamentalmente, um desvelamento do processo dialético que ocorre entre subjetividade e objetividade, ou seja, a objetividade da vida do indivíduo se torna subjetiva e essa subjetivação se objetivará através da sua ação. $O$ que quer dizer que os indivíduos em conjunto produzem seu ambiente, com a totalidade de suas formações psíquicas, sociais e culturais e, dentro dessa configuração, o ser humano se vale de ações habituais (Lefebvre, 1991; Heller, 1977, 1989).

$\mathrm{Na}$ cidade as representações afetam e são afetadas pelas características pessoais dos habitantes e por seu comportamento espacial. Todo espaço é uma imagem de nossa cultura. Os ambientes arquitetônicos e também os urbanos criados pelo homem são a expressão de processos de filtragem cultural e permitem desvelar como os diferentes povos usam seus sentidos (Fischer, 1997). Seja numa cidade, num escritório ou numa casa, as dimensões ocultas (parafraseando E. Hall) da cultura estarão colocadas mesmo que não as procuremos ou não as tornemos explícitas, seguindo numa linguagem silenciosa (parafraseando $\mathrm{E}$. Hall). A humanidade tende a identificar sua própria imagem àquela do espaço que ela habita. Transformando os espaços em lugares significativos a apropriação é por nós conquistada em dois sentidos, um que se dirige aos outros na conquista do espaço e outro a si mesmo, quando procura adaptar o espaço às próprias necessidades. Esses processos de apropriação inauguram elementos únicos que devem ser estudados separadamente. Entretanto eles possuem elementos unificadores comuns. As características desses elementos estão enraizadas na complexidade e particularidade de cada um desses níveis. Portanto, devese prestar atenção aos elementos que podem ser aplicados em todos os níveis da organização humana, seja ela individual ou grupal (Proshansky 1976, 1978; Ramadier, 1997; Kuhnen, 2002).

Deve-se reconhecer a importância que têm os mecanismos de apropriação de espaço e os elementos que o configuram, pois através de tais mecanismos os indivíduos são capazes de criar ou captar significados, simbolizando e interagindo com os mesmos, levando-os a incorporá-los à sua própria identidade. Nesse campo de interfaces, a simbolização é um processo a ser considerado, pois é através dela que as coisas e os espaços 
tornam-se relevantes para a experiência humana. Há situações simples na vida cotidiana que guardam em si a possibilidade de compreender o funcionamento de comunidades urbanas complexas no que concerne a problemas maiores, tais como as relações entre grupos, os serviços urbanos, 0 papel do bairro na vida da comunidade etc. Contudo, é preciso não perder de vista a dimensão de que não nos situamos somente em relação aos lugares, mas em relação aos outros também. Giuliani (2004), ao tratar do apego aos lugares, coloca-nos diante de uma importante indagação:"o apego a lugares e o apego em relações interpessoais compartilham as mesmas características definidoras?" (p. 96). É mais significativa a experiência direta, os contatos dentro de um lugar. Estudos de percepção ambiental e as condições nas quais os diferentes espaços são ocupados permitem avaliar qualitativamente a compreensão que se tem do meio ambiente. Entretanto, como bem adverte Thibaud (2004),"o perceber não pode ser reduzido a uma simples contemplação passiva do mundo. Ela envolve, grosso modo, agir de uma certa maneira" (p. 356). Ou, ainda,"perceber não apenas envolve distinguir os objetos no ambiente como também experienciar o estado do meio em um dado momento" (p. 360).

\section{Contexto do trabalho - panorama da investigação e da ação}

Já se sabe que os segmentos socioeconômicos desfavoráveis estão ainda mais limitados dos benefícios urbanos, não tendo acesso à diversidade que a cidade propicia aos grupos com melhor poder aquisitivo. Por certo, a cidade de Florianópolis, capital do Estado de Santa Catarina, apresenta características semelhantes às outras cidades, mas há algumas particularidades destacáveis. Vive um crescimento muito rápido num espaço de tempo relativamente pequeno. Segundo dados do IBGE (Instituto Brasileiro de Geografia e Estatística), em 1996 a população era de 271.281 habitantes. $O$ censo de 2000 indicou 331.784 habitantes. A maior parte territorial situa-se numa ilha e a outra pequena parte no continente próximo. Como cidade litorânea, atrai milhares de turistas nos meses de verão, férias e feriados em geral, aumentando consideravelmente o contingente humano. Tais fatores impõem-se sobre a vida de crianças e jovens pobres de forma muitas vezes cruel. Diante dessa realidade organizou-se o trabalho que aqui será apresentado. Fruto de projetos de extensão e pesquisa que objetivaram reconhecer os processos de apropriação de espaço e de representação ambiental operados por crianças moradoras de uma comunidade de baixo poder aquisitivo situada numa região periférica de Florianópolis, a Comunidade Chico Mendes. Essa comunidade convive com problemas sociais graves, como o tráfico, a violência, o desemprego e precárias condições ambientais. Seus moradores se caracterizam por serem, na sua maioria, migrantes que vêem na capital uma oportunidade para melhorarem 
de vida. Porém esse sonho muitas vezes não se concretiza, o que resulta na queda da qualidade de vida das famílias e que, num contexto mais amplo, agrava os índices de desigualdade social. Os projetos desenvolveramse junto à proposta da Associação dos Amigos do Centro de Atividades Comunitárias Chico Mendes - denominada Casa. É imerso nesse contexto que surgiu nosso problema de pesquisa: entender como a cidade e a comunidade são percebidas pelas crianças e jovens e como se dá o processo de apropriação desses espaços. Iniciou com um estudo exploratório, onde se observou as crianças e suas formas de interação, conheceu-se a comunidade e a forma como as crianças se relacionam com ela, além de ter sido um momento importante para a construção de vínculo com as crianças, professores, dirigentes da Casa e comunidade com os investigadores. Deuse então um formato com o projeto de extensão Aspectos Psicológicos das Interações Humano-Ambientais/ Relação Sócio-espacial e Desenvolvimento da Identidade de Lugar. Identificaram-se, então, múltiplas repercussões do contexto espacial sobre a vida das pessoas. Em especial, o fenômeno de desterritorialização e diluição de sociabilidades entre as crianças. Vinculouse tal estado à fragilidade ao sentimento de apropriação e apego ao local de moradia. $O$ trabalho de extensão centrou-se, a partir desse diagnóstico, no desenvolvimento de tarefas que pudessem diminuir esse fenômeno local e capacitar a comunidade a produzir sentido e a apropriar-se do seu entorno. Buscou-se, então, garantir que junto ao processo de apropriação houvesse elementos essenciais de mecanismos de socialização (Kuhnen, Drews, \& Luz, 2004; Kuhnen, Silveira, \& Hortal, 2004). A partir dessa inserção, articulou-se um problema de pesquisa: As Construções Simbólicas do Espaço Urbano para Crianças e Jovens. Foram fundamentais as observações livres e participantes (Delhomme \& Meyer, 1997) que levaram a investigação a dirigir-se à apreensão da espacialidade, dos contextos de apropriação espaço-temporal, correlacionando-os ao desenvolvimento e à identidade dos sujeitos e aos aspectos cognitivo-emotivos, alcançando situações que enfatizavam a relação com a cidade. Estando unidas, desde o princípio, a construção como processo e a construção como produto, optou-se aqui por mostrar a imbricação destas no desenvolvimento de ações dos dois projetos. As estratégias agregaram vários métodos ou técnicas de pesquisa social que pudessem captar as informações na participação ativa dos envolvidos. Trabalhos grupais foram privilegiados para lidar com a dimensão coletiva e interativa da investigação. Também se utilizaram técnicas de registro e de processamento de dados.

Reconhecidamente as ciências humanas e sociais utilizam diversas estratégias de pesquisa. Rivlin (2003), ao fazer uma revisão dos pressupostos que guiaram os primeiros trabalhos de psicologia ambiental, indica o uso de múltiplos métodos no estudo das experiências humanas como um dos pressupostos básicos do campo, reafirmando que "a identificação da dinâmica que elementos específicos da experiência de lugar de uma pes- 
soa pode evocar, e o uso de procedimentos de escrita, fotografia e desenho, podem desvendar pelo menos algumas das partes constituintes daquilo inicialmente percebido como um campo unitário" (p. 217). Tais alicerces metodológicos e o uso de variados métodos de investigação nos assegurou o alcance da meta de se estudar a relação pessoa-ambiente. A escolha pautou-se na idéia de oportunizar uma apreensão a mais ampla possível do repertório dos sujeitos sob variadas formas de expressão. O método contou com um desenho prévio e foi sendo estruturado, tomando formato durante o processo de trabalho, a partir das respostas que o grupo apresentava. Após cada encontro os resultados eram avaliados pelos investigadores e esboçadas novas atividades. A esse movimento Flick (2004) dá o nome de circularidade do processo, método que "obriga o pesquisador a refletir permanentemente sobre todo o processo de pesquisa e sobre etapas específicas à luz das outras etapas" (p. 60). A partir de suas manifestações interpretamos a relação que estabelecem com o ambiente. Como está e se dá tal relação foi buscado indiretamente dentre as expressões que foram alcançadas através das observações livres, dos passeios pela cidade, dos relatos presentes nos discursos, seja provenientes das entrevistas ou dos depoimentos livres, durante as atividades artísticas e outras, ou através da concretização em desenhos, na elaboração de diagramas e na "revelação" das fotografias que fizeram livremente do local onde moram.

\section{Posicionamento nos lugares: a observação}

Observar implicou registrar a maneira como os sujeitos se colocavam num determinado lugar, e até mais do que isso, como interagiam entre si, com o meio e com os objetos disponíveis. Finalmente podemos dizer que o produto dessa técnica ofereceu dicas de como os sujeitos utilizam, como circulam ou se relacionam com o espaço, já que se pautou na idéia de que "o objetivo dos métodos de observação é de compreender como as pessoas se comportam no ambiente e como o ambiente pode modificar seus comportamentos" (Uzzell \& Romice, 2003, p. 66). Outra forma foi observar interações sociais fazendo parte de uma totalidade social. Seguimos as cinco etapas indicadas por Delhomme e Meyer (1997, p. 167) para o desenvolvimento de uma observação participante. Entre elas destacam-se a de "se familiarizar com o ambiente (lugar etc.), os membros do grupo (seu nome, função, o que fazem etc.), a organização social, os acontecimentos. Estabelecer, se possível e desejável, relações com os membros do grupo estudado". 


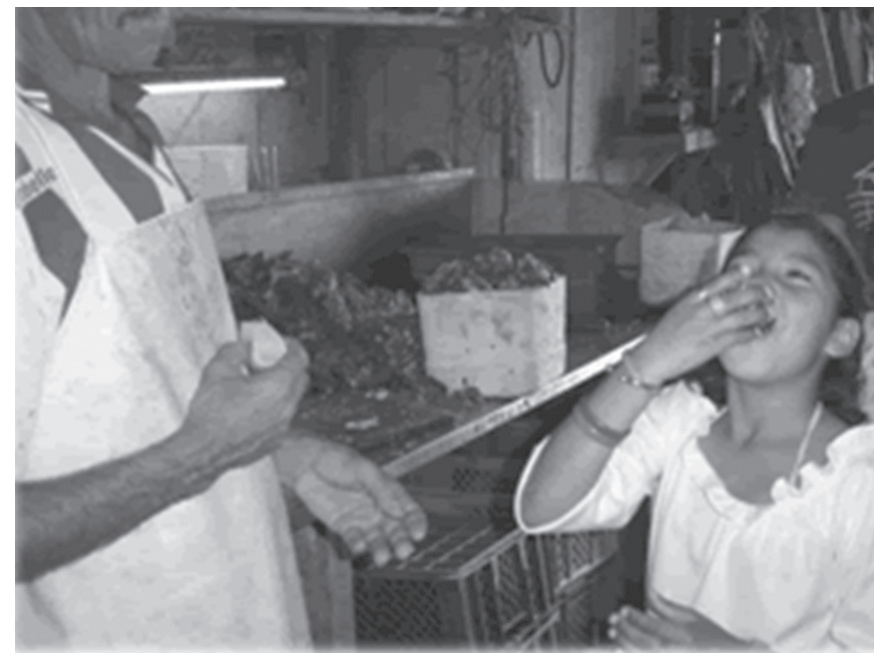

Figura 1. Menina degustando ostra.

\section{Os encontros-passeio}

Os passeios em espaços da cidade concretizaram-se numa fase importante do trabalho, uma vez que seu objetivo extrapolava um fim recreativo e foram planejados para possibilitar o contato com as pessoas, o andar pela cidade, olhar e sentir o que lhe é próprio. Visualizava-se na movimentação, que leva à experimentação, uma pré-condição para a percepção e a cognição ambiental. Ao receber informações do meio e de si mesmas, as crianças apropriam-se do meio e adquirem noções de si (Rabinovich,2004). Ofereceu-se ao grupo uma oportunidade (para a maioria, a primeira) de estar, agir num meio desconhecido e complexo, repleto de novidades, rico e estimulante em elementos naturais e construídos, que permitisse explorar, construir estruturas cognitivas e apego aos lugares. Os três primeiros encontros foram destinados a passeios por locais públicos e em distintas regiões geográficas da cidade (parque no centro, bairro histórico, praia e exposição na universidade com brincadeiras no bosque). As atividades iniciavam-se na própria comunidade. Referendados em mapas simplificados, o percurso era indicado. Cada criança ganhava um exemplar para identificar o ponto de partida, os locais de parada, as ruas e avenidas do percurso e o local de visita. Durante os trajetos, foram estimuladas a se situar e a observar pontos específicos e de referência urbana. Ao chegar aos locais, uma pequena explanação era feita acerca das características locais. Em seguida eram deixadas à vontade para interagirem com as pessoas que transitavam e com o espaço físico. A Figura 1 revela crianças degustando ostras e a Figura 2 crianças entrando em contato com o mar e a pesca. 


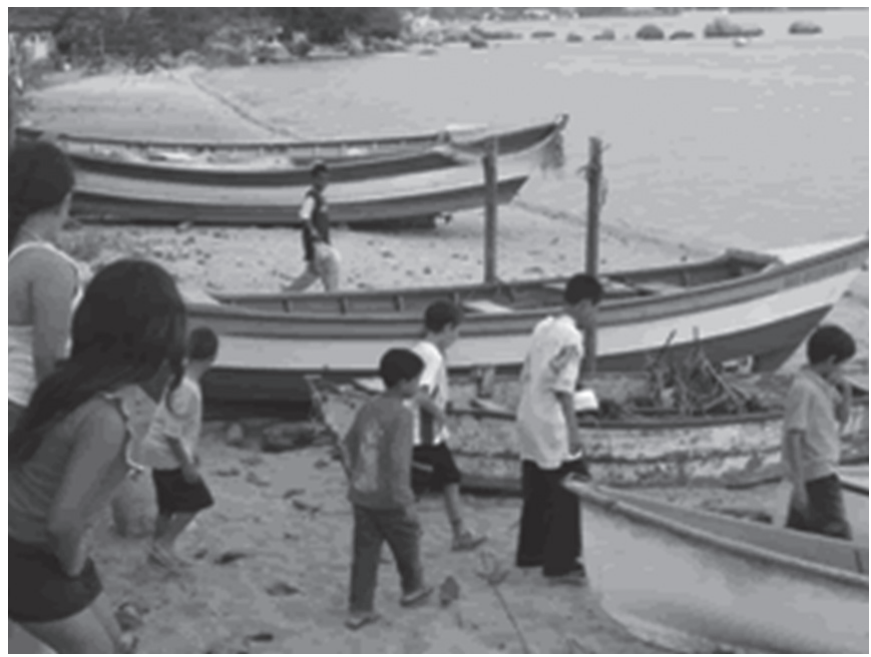

Figura 2. Conhecendo o mar e a pesca.

\section{Os encontros temáticos}

Para esses encontros foram propostos quatro temas norteadores evocadores de conteúdo. A partir desses temas foram elaborados cinco grupos de atividades compreendidas entre entrevistas semi-estruturadas, atividades lúdico-expressivas, desenhos, diagramas e fotografias. Os temas norteadores foram pensados a partir da leitura do trabalho desenvolvido por Castro (2001 b) e equipe com as Oficinas da Cidade. Adaptados à nossa meta e realidade ficaram com a seguinte configuração: tema 1 - A Cidade e a Comunidade; tema 2- Construindo a Cidade; tema 3 - Sonhando a Cidade; e tema 4 - A Cidade Possível (ou A Cidade que Queremos). Os encontros temáticos estão detalhados na Tabela 1. Para executar a primeira fase do trabalho foram necessários três encontros de duas a três horas cada e aconteceram na Universidade Federal de Santa Catarina, numa das salas do SAPSI - Serviço de Atendimento Psicológico, do Departamento de Psicologia. Integravam o grupo dezesseis crianças, de idade entre sete e onze anos, as quais foram divididas em subgrupos, com oito crianças cada. O que orientou a seleção foi o equilíbrio entre gêneros e afinidades entre as crianças. Dos investigadores, um dirigia a atividade e outro observava, anotando informações, gravando e fotografando. Também auxiliava o coordenador, caso fosse necessário.

Previu-se que a entrevista semi-estruturada garantiria que os sujeitos construíssem seu discurso, fazendo as conexões que seriam mais relevantes. As atividades chamadas lúdico-expressivas foram planejadas com jo- 


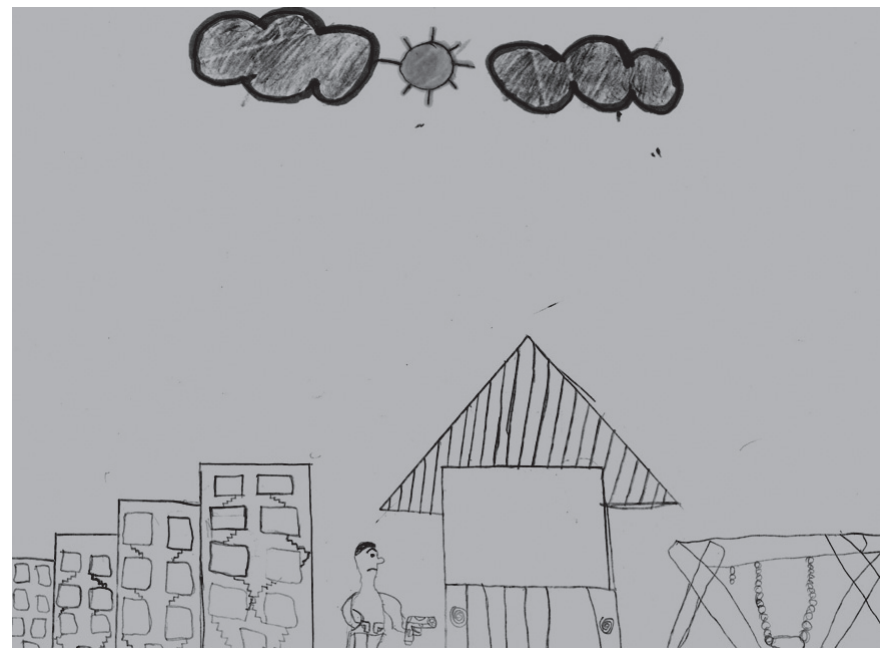

Figura 3. Homem com arma na mão ao lado do parquinho.

gos e brinquedos previamente selecionados. Utilizou-se o desenho como forma de concretizar as representações das crianças sobre os temas de cada encontro. $O$ desenho constitui-se por si só numa atividade simbólica. A partir dele reduziu-se a ansiedade, organizou-se informações e processaram-se experiências. $O$ desenho é antes de tudo uma forma de expressão que pode ser utilizada para revelar aprendizado, auxiliando-o, ao mesmo tempo em que desenvolve e representa o mundo (Golberg, Yunes, \& Freitas, 2005). Em todos os encontros houve um tempo destinado à atividade de desenhar, pois além de ser, para essas crianças, uma atividade prazerosa, permitiu recordarem-se dos encontros e expressar, objetivando o mais significativo, para os investigadores concretizarem um momento de aprofundamento individual com cada criança. No final das atividades as crianças produziram 33 desenhos (Figuras 3 e 4). Com a utilização dos diagramas (Figura 5) criou-se uma possibilidade de sintetizar os temas dos encontros em palavras que identificassem os significados atribuídos à cidade. A idéia surgiu a partir do recurso à livre associação (Gaskell, 2002, p. 80).

O tema A Cidade e a Comunidade buscou a relação das crianças com os espaços em que vivem, circulam, freqüentam e as atividades desenvolvidas. Esse material auxiliou a entender como se dá a apropriação dos espaços, uma vez que, através deles (mecanismos de apropriação), os indivíduos são capazes de criar ou captar significados, simbolizando e interagindo com os mesmos. Nesse momento foi utilizada a entrevista. $O$ segundo tema, Construindo a Cidade, almejou indicar elementos presentes na cidade. Empregaram-se atividades lúdico-expressivas com a brincadeira da 


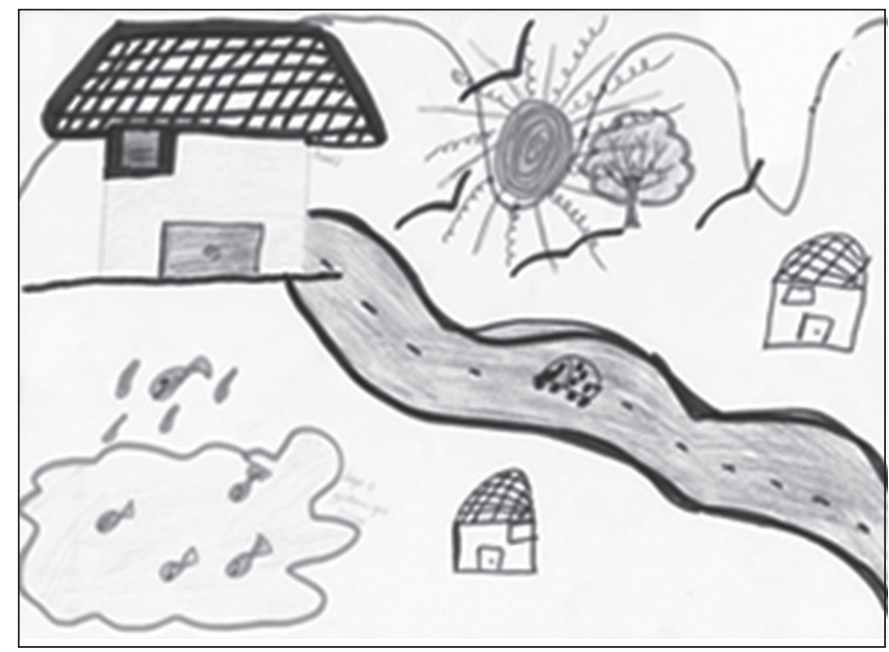

Figura 4. Um passeio.

história no tapete; em seguida, o desenho e o diagrama. Os temas seguintes, Sonhando a Cidade e A Cidade Possível, respectivamente, atingiram os elementos que as crianças planejavam para uma cidade imaginável, onde os sonhos e as fantasias expressas indicariam uma cidade onde o real e o imaginário conjugassem num só projeto. Para realização dessas, utilizou-se o desenho e o diagrama (Figura 5).

As tarefas estão detalhadas a seguir na Tabela 1.

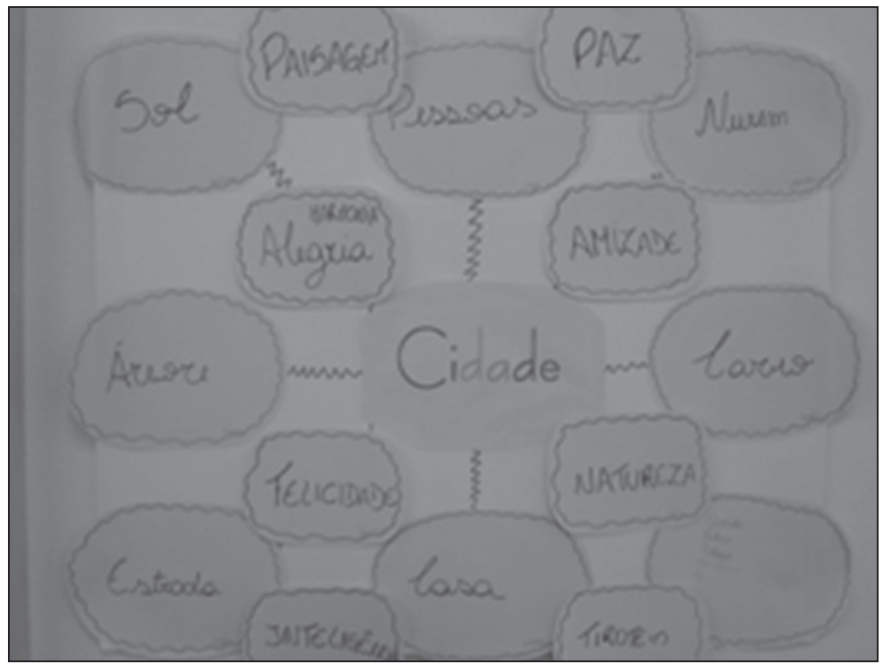

Figura 5. Exemplo de diagrama. 
Tabela1. Roteiro de atividades para os Encontros temáticos

\begin{tabular}{|c|c|c|c|c|}
\hline Tema & $\begin{array}{l}\text { Pergunta } \\
\text { norteadora }\end{array}$ & Atividade & Objetivo & Resultados \\
\hline \multirow{3}{*}{ 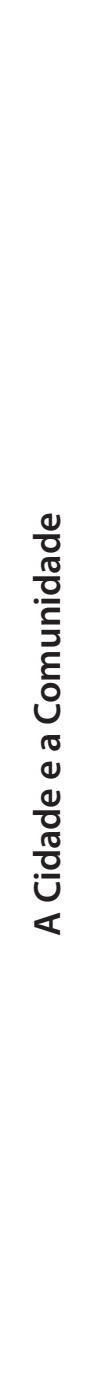 } & \multirow{3}{*}{$\begin{array}{l}\text { Como as } \\
\text { crianças } \\
\text { percebem } \\
\text { a cidade e a } \\
\text { comunidade } \\
\text { em que } \\
\text { vivem? }\end{array}$} & $\begin{array}{l}\text { Aquecimento: Registro de } \\
\text { dados como nome, idade, } \\
\text { escolaridade, etc. }\end{array}$ & $\begin{array}{l}\text { Preparar o clima } \\
\text { para as atividades } \\
\text { que seriam } \\
\text { propostas; } \\
\text { Habituar as } \\
\text { crianças à sala e aos } \\
\text { gravadores e outros } \\
\text { equipamentos. }\end{array}$ & $\begin{array}{l}\text { Diminuição da } \\
\text { ansiedade dos } \\
\text { pesquisadores } \\
\text { e sujeitos da } \\
\text { pesquisa. }\end{array}$ \\
\hline & & $\begin{array}{l}\text { Entrevista semi- } \\
\text { estruturada sobre a cidade. }\end{array}$ & $\begin{array}{l}\text { Fazer levantamento } \\
\text { de locais conhecidos } \\
\text { e freqüentados, } \\
\text { que atividades } \\
\text { desenvolvem } \\
\text { nestes locais, quais } \\
\text { gostariam de } \\
\text { conhecer, etc. }\end{array}$ & $\begin{array}{l}\text { Os passeios, que } \\
\text { fizeram com as } \\
\text { bolsistas, com } \\
\text { a escola, família } \\
\text { e com o Projeto } \\
\text { Esperança foram } \\
\text { presentificados. }\end{array}$ \\
\hline & & $\begin{array}{l}\text { Entrevista semi- } \\
\text { estruturada sobre a } \\
\text { comunidade. }\end{array}$ & $\begin{array}{l}\text { Fazer levantamento } \\
\text { dos locais que } \\
\text { conhecem, onde } \\
\text { brincam, quais são } \\
\text { as brincadeiras, com } \\
\text { quem brincam, etc. }\end{array}$ & $\begin{array}{l}\text { Obtenção de } \\
\text { elementos para } \\
\text { entender como } \\
\text { são as relações } \\
\text { na comunidade e } \\
\text { seu cotidiano. }\end{array}$ \\
\hline
\end{tabular}




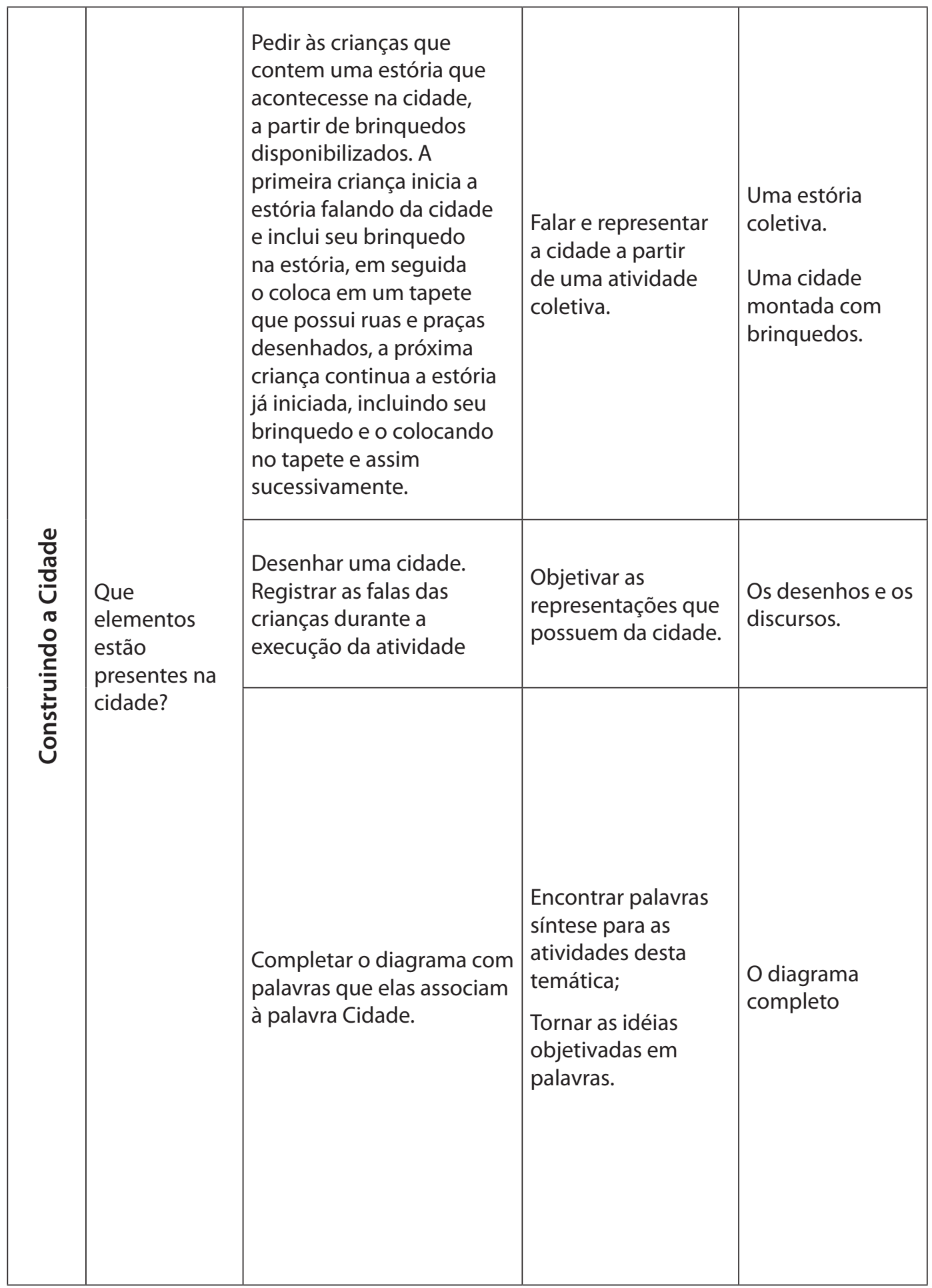




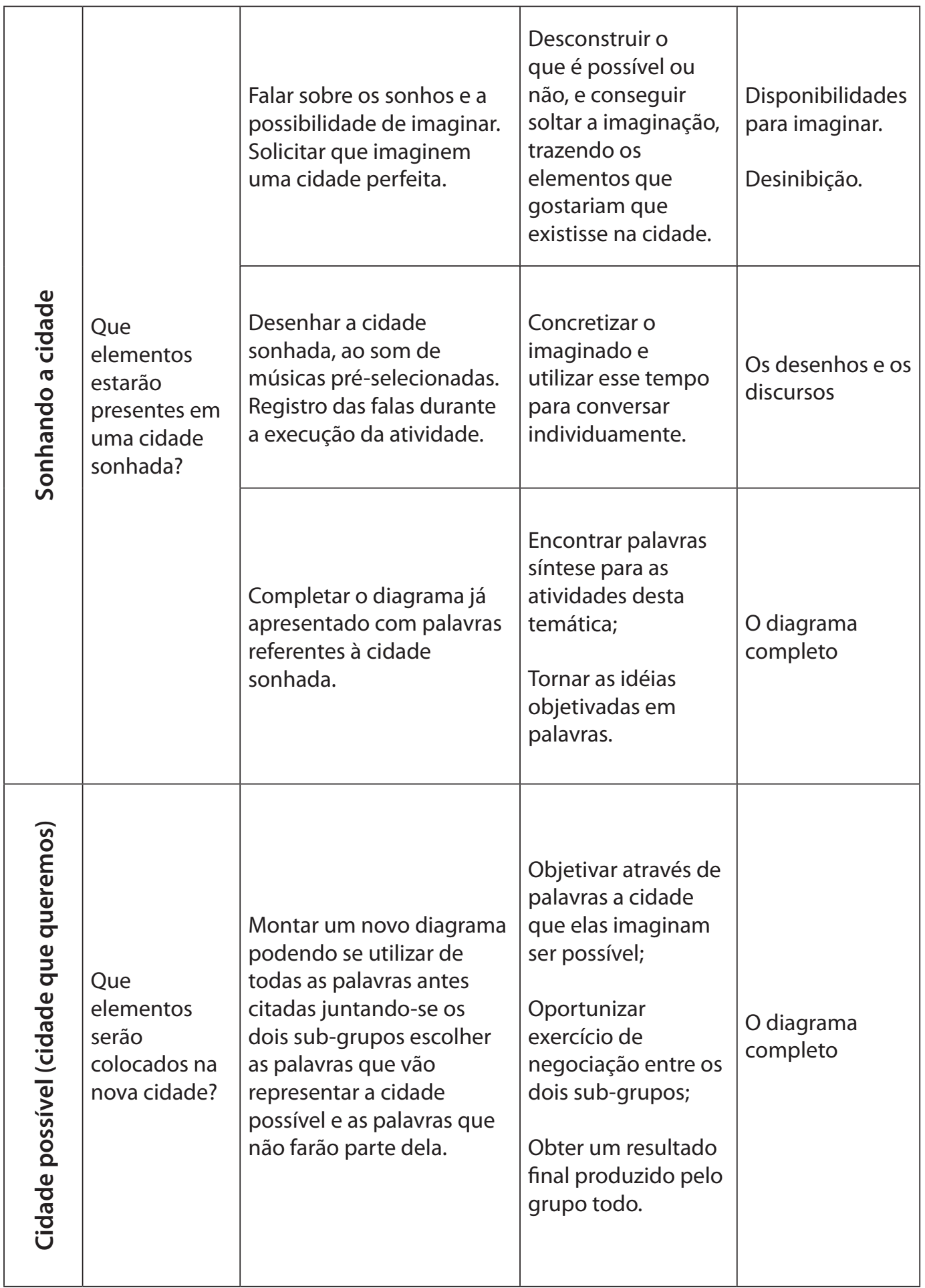


Para finalizar a investigação em campo, uma segunda etapa foi pensada. Agora, no próprio local de moradia, foi oferecido ao grupo de crianças câmeras fotográficas. Receberam a tarefa de registrar a comunidade pensando em lugares significativos para si. Essa técnica é chamada por Higuchi e Kuhnen (2004) de fotografando ambientes. Com essa atividade foi possível captar cenas da comunidade através do olhar das crianças. Freqüentemente, crianças apresentam dificuldade em verbalizar relações sociais, assim como seus diferentes contextos de vida. Para Neiva-Silva e Koller (2002), "quando uma pessoa direciona a câmera fotográfica para determinado objeto, símbolo, evento, pessoa ou lugar, em resposta a uma pergunta, e capta esta imagem através da fotografia, naquele instante ela passa a mostrar algo de si" (p. 12). Esteve sob nossa análise a escolha do foco e os conteúdos que as inspiraram na busca da imagem para representar a indagação. Cada autor escolheu uma delas para fazer parte da mostra que foi organizada no Centro de Ciências Humanas da UFSC e na Casa. Atualmente, decoram as salas da Casa. As produções fotográficas possibilitaram uma análise qualitativa crucial para compreensão de alguns processos socioambientais desse grupo, por exemplo, revelando um certo "olhar" ao lugar de moradia, que foi freqüente nas imagens, assim como para Higuchi e Fernandes (2002), ao usarem a técnica do ambiente fotografado com crianças vizinhas de uma reserva florestal. Lá observaram que o ambiente natural forma um ambiente lúdico e de refúgio que se contrapõe com a pobreza e violência vivida no dia-a-dia pelas crianças e suas famílias. As crianças da Comunidade Chico Mendes ilustraram para si, para o grupo e para os expectadores de suas imagens como acontece o entrecruzamento do espaço físico com as dinâmicas sociais no bairro onde moram. Os registros auxiliaram na incorporação da problemática ambiental ao vivido. $O$ bairro está sendo remodelado por prédios habitacionais populares. $O$ choque que enfrentam com a destruição de suas antigas casas foi registrado em muitas fotos (Figura 6).

\section{Olhando numa nova posição - alcances e perspectivas}

Observando os aspectos humanos inerentes aos problemas ambientais, esses projetos trouxeram à tona características psicológicas dos sujeitos que interagem com as do ambiente e especialmente nas implicações que essa inter-relação exerce nas representações, na cognição e nos comportamentos. Tão somente pelo fato do ambiente ser participante no processo de elaboração da consciência ao interagir com ele, o ser humano altera a realidade. Tal troca influencia decisivamente na construção de sua visão de mundo. De igual forma, se a humanidade usa o espaço como forma de linguagem e o manipula num constante processo de construção de sua identidade, este também precisa estar presentificado. Para entender 


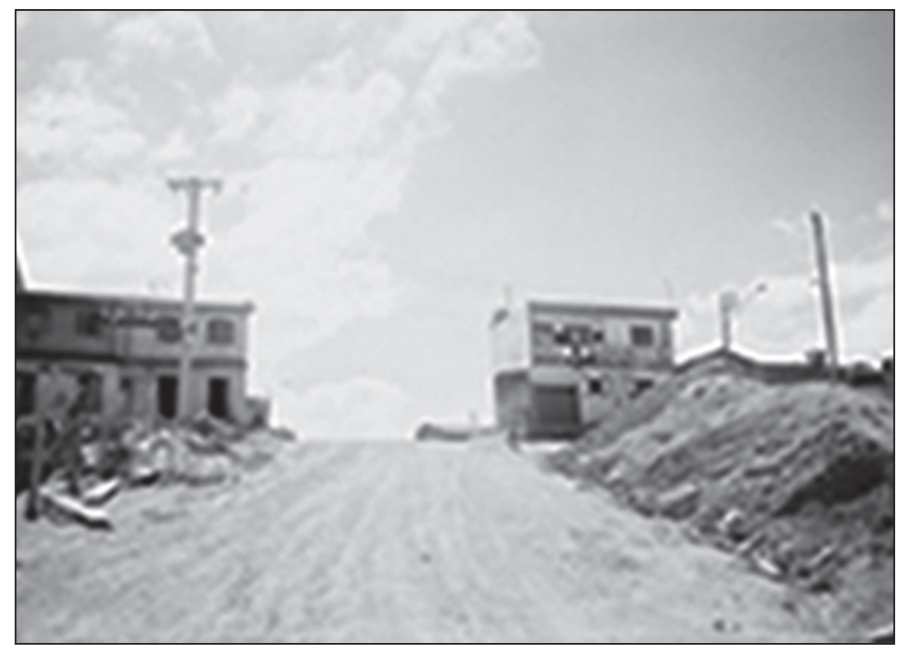

Figura 6. Comunidade em processo de reestruturação.

essa dinâmica foi necessário acessar eixos emotivo-cognitivos subjacentes às suas ações e o comportamento dessas crianças. Conhecendo o contexto ambiental no qual o comportamento ocorre, expôs-se como se encontram os significados relativos ao ambiente. Verificou-se, por fim, que o conhecimento relativo ao meio ambiente foi construído a partir das experiências diárias em que os sujeitos se encontravam engajados. Processo que se deu por meio de experiências de vida marcadas pela complexidade de relações nos campos da educação e da afetividade. Por exemplo, a idéia de favela como um lugar indesejável é tomada como verdade por estas crianças quando descrevem os valores culturais e comparam-se com as pessoas que vivem em lugares mais prósperos. Ao mesmo tempo em que lutam contra imagens discriminatórias vinculadas às pessoas da favela, também produzem outros sentidos, já que criam uma imagem, dividindo os habitantes da favela entre trabalhadores e marginais, honestos e bandidos, calmos e violentos. Podemos assim observar em suas próprias falas. Na atividade de reflexão sobre a cidade, respondendo à pergunta "Como são para as crianças as pessoas que vivem na Cidade real?",E. afirma: são"branca, galega, feia, bonita, com cabelo, sem cabelo", L. complementa: "morena; às vezes tem umas que tem amigos, às vezes tem umas que não tem", D. integra-se para dizer: "são tudo casqueiro" e D. explica: "ficam debaixo da ponte pedindo pó". Outras trabalham, dizem alguns. E. diz que "tem gente pobre e gente rica"; para A. "trabalham pegando coisa no lixo". O que os pobres fazem? Para E.,"trabalham, só que não são muito bem de vida"; G. interfere:"procuram emprego" e D. termina ironizando:"tem uns que tanananannnn". 
Cada vez menos têm em mente que a classe operária poderá chegar ao paraíso (como no filme de Elio Petri), a violência toma conta das relações, o ambiente é degradado e nem sequer sonhar se faz presente. Joel Birmam (2005) expressa fielmente essa situação quando afirma que "a violência, a delinqüência e a criminalidade constituem o positivo da fotografia revelada, cujo negativo é produto do amálgama existente entre a sociedade civil e a sociedade política brasileira... o que se inscreve nas margens da sociedade brasileira é o que revela o seu fundamento, numa perspectiva simbólica e genealógica". Fotografias reveladas que representam a visão focada pelas crianças em sua comunidade. Podemos ver a degradação resultante da destruição das antigas casas construídas por seus familiares ou quando foram obrigatoriamente removidos para as novas residências em prédios. Quando Amphoux (2003) brinca com as palavras, dizendo "faire parler les gens des lieux pour faire parler les lieux" (p. 227), arriscando-se, numa tradução livre, tem-se a idéia de que ao levar as pessoas dos lugares a falarem, falam os lugares, o autor nos alertou para o que chama de qualidade sensivel dos ambientes, o que somente se pode acessar de forma indireta. Conteúdo mais indicado à interpretação do que à explicação.

Resistência e revolta estavam presentes nas ações e discursos das crianças que desejavam ficar em suas casas, manter as relações de vizinhança construídas ao longo dos anos e ter ruas livres para brincar. O local foi reestruturado pela Prefeitura Municipal, que planejou uma ampliação da via de acesso à cidade dentro da área da comunidade, remodelando o espaço e diminuindo a área em que moravam (Figura 6). Há, ainda, na visão das crianças, a presença concreta da violência vivida. Num dos desenhos (Figura 3), observa-se a concretude dos discursos na presença de um homem empunhando arma de fogo. Na atividade de construção da cidade (cidade real) a coordenadora da atividade dispõe os brinquedos. G. e D. os escolhem e vão expressando o que fazem. Incluem o "exército prá defender, defender a nossa cidade." Ao serem indagados do que ou de quem, D. responde "eu" e G. "os ladrões", e estes "roubam e matam". Mais adiante são questionados a respeito das pessoas. E. diz que só tem soldados e, quanto às pessoas, "elas estão dentro das casinhas por que tá dando tiro."O que D. complementa, "está tendo guerra". No mesmo desenho se vê, ao lado do homem empunhando a arma, o parquinho onde brincam; ao lado dos prédios se representam os conjuntos onde vivem na Comunidade Chico Mendes. Fazem referência a esses elementos na brincadeira no tapete. Orientados, se imaginam andando na cidade e lá A. encontra "tubarão, avião"; D. vê "casa, carro, pombinha, passarinho, tartaruga, luz, casa, televisão, tem nuvem."Para E:"Tem mar, loja, cachorrinho, parque"; L:"Tem cavalo"; Para F: "Árvore"; E. recorda: "Cachorro-quente, comida"; e D:"Tem a faculdade"; A: "Tem lápis", E:"Comida"; L:"Homem bonito."Entretanto; ao serem indagados se é legal morar nessa cidade, E. acha legal, mas D. retruca demonstrando indignação: "É legal né, ouvir os tiros de noite". Quando se busca saber o 
que se faz nessa cidade, se tem lugar pra brincar e onde se localiza, E. diz que:"Brinca, anda de carro, vai passear."Então E. se refere ao parquinho. Mas D. interfere:"Uh! Aquele parquinho é bem ruim, todo quebrado, todo desmontado."Mais adiante, ao fazerem referência à comunidade, E. mostra que lá "é bem legal, a gente brinca". Num processo contínuo e inacabado, vê-se que essas crianças, estando privadas de estar e conviver na cidade, estão também privadas como sujeitos em desenvolvimento, já que não se beneficiam de elementos que a cidade apresenta, desde suas variadas construções, expressões dos modos de vida, até os diferentes valores e culturas que convivem na vida urbana.

A renovação do ambiente urbano deve ser visada para que possa atender os preceitos do desenvolvimento humano saudável. Um desses cuidados é pensar que a cidade deve atender às necessidades das crianças e jovens, ampliando relações sociais, lógicas de contratualidade, identificação e pertencimento social. As investigações acerca das transformações subjetivas próprias da vida urbana oferecem entendimento dos sentidos ético-políticos a ela relacionados. É preciso ver surgir interesses voltados a enfrentar os efeitos dos problemas urbanos e ecológicos no desenvolvimento infantil, ou seja, parece que "uma idéia nova se afirma há alguns anos: o direito da criança à cidade e a necessidade de transformá-la para responder às suas necessidades, às suas aspirações. A abertura e a integração sucedem, assim, à exclusão e à reclusão" (Mekideche, 2004, p. 148). A participação ativa das crianças e também de outros grupos excluídos, como os jovens e os idosos, na construção coletiva da cidade onde moram, oportunizaria cenários de aprendizagem além dos domínios da escola e da casa.

\section{Considerações finais}

Historicamente, a noção de cidade esteve vinculada à de civilização (participação, cidadania, civitas e polis) e essa à de educação. Na atualidade, estando o conceito de cidade bastante vinculado ao conceito de espaço público, especialmente como lugar de crise e conflito (superpopulação, exclusão, violência, desemprego, solidão, poluição), impõe-se a necessidade de redefinição enquanto espaço coletivo, para que possamos trilhar um caminho que leve à resolução ou mesmo a uma remediação do problema urbano que criamos para nossa sociedade. Se não o fizermos para nós próprios, que tenhamos pelo menos a decência de tentar deixar alguma contribuição às novas gerações, para que elas construam cidades diferentes daquelas que deixamos para elas. Ou seja, "a resolução do problema urbano é hoje uma espécie de medida do desenvolvimento humano" (Carneiro, 1999, citado por Gómez-Granell \& Vila, 2003, p.18). O entendimento de que a configuração do espaço físico pode facilitar ou inibir as interações sociais resultará, por exemplo, em importantes implicações no que tange 
às políticas públicas. Se admitirmos que a qualidade dos ambientes naturais seja um atributo importante nas regulamentações da vida social nas cidades, devemos ter em mente que fornecer subsídios claros aos planejadores ampliará as possibilidades de oportunizar ambientes que incluam paisagens e aspectos apreciáveis pela população. A apropriação tem o papel de transformar espaços em lugares significativos para a pessoa ou grupos. Mas "tanto sentir-se parte, como identificar-se constituem condições subjetivantes da cidadania, isto é, só haverá exercício efetivo da cidadania quando este sujeito - criança e jovem - encontre condições que favoreça seu pertencimento e sua identificação a algo maior que é a sua nação ou $o$ seu Estado" (Castro, 2001b, p. 117).

A geração de conhecimento nessa direção torna-se importante pela criação de condições para uma real evolução da Psicologia num exercício interdisciplinar. A psicologia ambiental, vinculada a outras áreas do saber, tem grande potencial para estudar a participação dos seres humanos na determinação, individual e coletiva, da qualidade de vida dos ambientes. A pesquisa executada buscou ampliar o escopo de participação da área criando novos campos de atuação profissional.

\section{How children understand, idealize and realize the place where they live}

Abstract: This article presents results of two co-related projects, one based on research and the other one of university extension. The objective is to understand the contexts of spatial and temporal appropriation of place and its implications on the citizens. The subjects are children living in a peripheral region of Florianópolis, in Santa Catarina. Diverse methods of research and intervention are used in the two projects. Amongst them are: field immersion, free and participant observation, directed interviews, strolls, playful activities, drawings and photographs. The methodology proves to be an important way to apprehend the reality, since they demonstrate perceptions and significances of the citizens. The theoretical sources that base the intervention and the analysis are primordially derived environmental psychology. Furthermore, the data was analyzed qualitatively. The results demonstrate that these citizens identify themselves with their community, however in relation to the other places of the city the phenomenon of "ghettofication" was verified and consequently they are unaware of the city beyond the limits of their neighborhood. The reflection of this limitation of and in the spaces of the city in the constitution of citizens was studied.

Keywords: Child. Appropriation. City. Poverty. Environment. 


\section{Comment les enfants perçoivent, idealisent et realisent le lieu où elles habitent}

Résumé: Cetravail présenteles résultats d'un projet de recherche et d'un travail d'extension universitaire sur le terrain, tous les deux ayant une proche correspondance. Ces projets ont pour cible connaître le contexte d'appropriation espace-temporel de lieu et les implications dans la formation des êtres-citoyens. Les sujets sont les enfants habitant un quartier dans la banlieue de la ville de Florianópolis, dans la province de Santa Catarina (sud du Brésil). La méthodologie utilisé dans les deux projets en question incluent des méthodes varies d'investigation et d'intervention. Parmi ceux - ci on peut citer l'immersion sur le terrain, l'observation libre et participante, des interviews, des sorties dirigées avec les enfants, activités ludiques, dessins et de la photographie. Les ressources méthodologiques mis en oeuvre ont démontre qu'ils constituent un important outil de appréhension de la réalité, dans la mesure où ils ont perçu les perceptions et significations des sujets. Les sources théoriques qui sont a la base de l'intervention et de l'analyse des donnés sont du domaine de la psychologie de l'environnement. Les résultats montrent que les sujets ont une identité avec leur communauté, cependant par rapport a des autres quartiers de la ville, on a vérifié un phénomène de "ghettoïsation" et par conséquent, les sujets ne connaissent pas la ville au delà du limite de leur quartier. Cette limitation de et dans les espaces de la ville contribuent decisivement dans la constitution des sujets - citoyens.

Mots-clés: Enfant. Appropriation. Ville. Pauvreté. Environnement.

\section{¿Cómo los niños, perciben, idealizan e interactuam en el lugar donde viven?}

Resumen:Este trabajo presenta el resultado de dos projectos,uno de investigación y otro de intervención comunitária que se co-relacionan. Objetibaron conocer los contextos de apropriación de espacio-tiempo del lugar y su relación con la formación y la participación ciudadana de los individuos. Los participantes fueron niños que vivian en la región de periferia de la ciudad de Florianópolis, capital de la provincia de Santa Catarina, Brasil. Fueron utilizados en los dos projectos diferentes métodos de investigación y intervención. Destacanse el processo de inmersión en el campo de actuação y de pesquisa, através de la observación libre y participante, entrevistas, paseos dirigidos, actividades lúdicas, dibujos y fotografias. Los recursos metodológicos comprobadamente demostraron los diferentes modos de apropriación de la realidad, pues evidenciaron las percepciones y significados de los participantes envolvidos. Las fuentes teoricas principales que fundamentaron la intervención y el análises fueron del campo de la psicologia ambiental. Los datos fueron analisados cualitativamente. Los 
resultados demostraron que los participantes tenian una indentidad con la comunidad, no siendo lo mismo, en relación a los otros lugares de la ciudad, observandose el fenomeno de la "guetificación" y consequentemente el desconocimiento de la ciudad mas alla de su barrio. Se constató que esa limitación de los y en los espacios se refleja en la constituición de la indentidad y ciudadania de los individuos.

Palabras clave: Niños. Apropriación. Ciudad. Pobreza. Medio ambiente.

\section{Referências}

Amphoux, P. (2003). L'identité sonoro urbaine, une approche méthodologique croisée. In G. G. Moser \& K. Weiss, Espaces de vie - aspects de la relation hommeenvironnement (pp. 201-220). Paris: Armand Colin.

Birmam, J. (2005, 4 de setembro). Uma nação de invejosos. Folha de São Paulo, pp. 4-5.

Campos-de-Carvalho, M. (2003). Pesquisas contextuais e seus desafios: uma análise a partir de investigações sobre arranjos espaciais em creches. Estudos de Psicologia, 8(2), 289-297.

Castro, L. R. de. (Org.). (2001a). Crianças e jovens na construção da cultura. Rio de Janeiro: FAPERJ.

Castro, L. R. de. (Org.). (2001b). Subjetividade e cidadania: um estudo com crianças e jovens em três cidades brasileiras. Rio de Janeiro: FAPERJ.

Delhomme, P., \& Meyer, T. (1997). Les projects de recherche em psychologie sociale (Collection Cursus). Paris: Armand Colin/Masson.

Elali, G. A. (2003). O ambiente da escola - o ambiente na escola: uma discussão sobre a relação escola-natureza em educação infantil. Estudos de Psicologia, 8(2), 309319.

Fischer, G.-N. (1997). Psychologie de L'environment social (2a ed.). Paris: Dunod.

Flick, U. (2004). Uma introdução à pesquisa Squalitativa (2a ed., S. Netz, trad.). Porto Alegre: Bookman.

Gaskell, G. (2002). Entrevistas individuais e grupais. In M. W. Bauer \& G. Gaskel, Pesquisa qualitative com texto, imagem e som. Um manual prático (pp. 64-89). Petrópolis, RJ: Vozes.

Granell, C. G., \& Vila, I. (2003). A cidade como projeto educativo (D. V. Moraes, trad.). Porto Alegre: Artmed.

Giuliani, M. V. (2004). O lugar do apego nas relações pessoas-ambiente. In E. T. O. Tassara, E. P. Rabinovich, \& M. C. Guedes (Orgs.), Psicologia e ambiente (pp. 89106). São Paulo: Educ.

Goldberg, L. G., Yunes, M. A. M., \& Freitas, J. V. de (2005). O desenho infantil na ótica da ecologia do desenvolvimento humano. Psicologia em Estudo, 10(1), 97-106. 
Higuchi, M. I. G. (2003). Crianças e meio ambiente: dimensões de um mesmo mundo. In F. O. Noal \& V. H. de L. Barcelos (Orgs.), Educação ambiental e cidadania - cenários brasileiros (pp. 201-229). Santa Cruz do Sul, SC: Edunisc.

Higuchi, M. I. G., \& Fernandes, D. A. (2002). Educação em verso e prosa com crianças da Colônia Chico Mendes. Manaus: INPA.

Higuchi, M. I., \& Kuhnen, A. (2004). Percepção e representação ambiental - métodos e técnicas de investigação para a educação ambiental. Manuscrito não-publicado.

Heller, A. (1970/1977). Sociologia de la vida cotidiana. Barcelona: Península.

Heller, A. (1989). O cotidiano e a história (3a ed.). Rio de Janeiro: Paz e Terra.

Kuhnen, A. (2002). Lagoa da Conceição - meio ambiente e modos de vida em transformação. Florianópolis: Cidade Futura.

Kuhnen, A., Hortal, M. M., \& Silveira, S. M. da (2004). Infância vulnerável e construção de significados - um projeto de psicologia ambiental. In Anais do 2 Congresso Brasileiro de Extensão Universitária. Belo Horizonte.

Kuhnen, A., Luz, G. M. da, \& Drews, A. (2004, maio). Aspectos psicológicos das interações humano-ambientais: relação sócio-espacial e desenvolvimento de identidade de lugar na Comunidade Chico Mendes-bairro Monte Cristo, Florianópolis, SC. Revista Extensio, 1(0), 1-6, maio. (Edição de lançamento)

Lefebvre, H. (1968/1991). A vida cotidiana no mundo moderno. São Paulo: Ática.

Legendre, A. (1999). Interindividual relationships in groups of young children and susceptibility to an environmental constraint. Environment and Behavior, 31(4), 463-486.

Lordelo, E. R., Carvalho, A., \& Koller, S. H. (2002). Infância brasileira e contextos de desenvolvimento. São Paulo: Casa do Psicólogo.

Neiva-Silva, L., \& Koller, S. H. (2002). O uso da fotografia na pesquisa em psicologia. Estudo de Psicologia, 7(2), 237-250.

Mekideche, T. (2004). Espaços para crianças na cidade de Argel:Um estudo comparativo da apropriação lúdica dos espaços públicos. In E. T. O. Tassara, E. P. Rabinovich, \& M. C. Guedes (Orgs.), Psicologia e ambiente (pp. 143-167). São Paulo: Educ.

Oliveira, C. (2004). O ambiente urbano e a formação da criança. São Paulo: Aleph.

Proshansky, H. M. (1976). Apropriation et non-apropriation (misapropriation de l'espace). In Actes de la conférence de Strasbourg: Appropriation de l'espace (pp. 3439). Strasbourg: P. Korosec-Sefaty.

Proshansky, H. M. (1978). The city and self-identity. Environment and Behavior, 10(2), 147-169.

Pechman, R. M. (1994). Apresentação. In R. M. Pechman (Org.), Olhares sobre a cidade (pp. 1-2). Rio de Janeiro: UFRJ.

Rivlin, L. G. (2003). Olhando o passado e o futuro: revendo pressupostos sobre as inter-relações pessoa-ambiente. Estudos de Psicologia, 8(2), 215-220.

Rabinovich, E. P. (2004). Barra Funda, São Paulo: as transformações na vida das crianças e na cidade - um estudo de caso. In H. Günther, J. Q. Pinheiro \& R. S. L. 
Guzzo (Orgs.), Psicologia ambiental: entendendo as relações do homem com seu ambiente (pp. 55-100). Campinas, SP: Alínea.

Ramadier, T. (1997). Évolution de la représentation cognitive de la ville: carte mentale et représentation conceptuelle de Paris. Psychologie Française, 42 (2), 191-192.

Thibaud, J-P. (2004). O ambiente sensorial das cidades: para uma abordagem de ambiências urbanas. In E. T. O. Tassara, E. P. Rabinovich \& M. C. Guedes, Psicologia e ambiente (pp. 347-361). São Paulo: Educ.

Tonucci, F. (2003). La ciudad de los niños (3a ed., R. Raschella, trad.). Buenos Aires: Losada.

Uzzell, D., \& Romice, O. (2003). L'analise des expériences environnementales. In G. Moser \& K. Weiss, Espaces de vie-Aspects de la relation homme-environnement (pp. 49-83). Paris: Armand Colin.

Veiga, E. V. (1993). Florianópolis: memória urbana. Florianópolis: EdUFSC.

Agradecemos às crianças e outros moradores da Comunidade Chico Mendes, ao coordenador e funcionários da Casa, aos alunos bolsistas do curso de Psicologia: Giordana M. da Luz, Giordana Marafon, Aline Drews, Ludmila Martins, Nadia R. Veriguini, Maisa M. Hortal, Frederico T.Gorski,Vinicius Martins e Scheila M. da Silveira e o apoio da UFSC pelo financiamento dos projetos através do Proextensão e Funpesquisa.

Ariane Kuhnen, Doutora em Ciências Humanas - Sociedade e Meio Ambiente pela Universidade Federal de Santa Catarina, professora do Departamento de Psicologia da Universidade Federal de Santa Catarina, onde também coordena o Laboratório de Psicologia Ambiental. Endereço para correspondência:Campus Universitário UFSC,Departamento de Psicologia, Florianópolis, SC, CEP 88040-970.Endereço eletrônico: ariane@cfh.ufsc.br

Scheila Machado da Silveira, Psicóloga, membro do grupo de pesquisa do Laboratório de Psicologia Ambiental da Universidade Federal de Santa Catarina e bolsista dos projetos "Aspectos psicológicos das interações humano-ambientais/relação sócio-espacial e desenvolvimento da identidade de lugar" e "As construções simbólicas do espaço urbano para crianças e jovens." Endereço eletrônico: scheilamachado@gmail.com

Recebido em: 8/08/2007

Aceito em: 24/03/2008 